\title{
Combination of biochar amendment and phytoremediation for hydrocarbon removal in petroleum-contaminated soil
}

\author{
Tao Han ${ }^{1}$ • Zhipeng Zhao ${ }^{1}$ • Mark Bartlam ${ }^{2}$ - Yingying Wang ${ }^{1}$
}

Received: 15 November 2015 / Accepted: 11 July 2016 /Published online: 4 August 2016

(C) The Author(s) 2016. This article is published with open access at Springerlink.com

\begin{abstract}
Remediation of soils contaminated with petroleum is a challenging task. Four different bioremediation strategies, including natural attenuation, biochar amendment, phytoremediation with ryegrass, and a combination of biochar and ryegrass, were investigated with greenhouse pot experiments over a 90-day period. The results showed that planting ryegrass in soil can significantly improve the removal rate of total petroleum hydrocarbons (TPHs) and the number of microorganisms. Within TPHs, the removal rate of total nalkanes $(45.83 \%)$ was higher than that of polycyclic aromatic hydrocarbons $(30.34 \%)$. The amendment of biochar did not result in significant improvement of TPH removal. In contrast, it showed a clear negative impact on the growth of ryegrass and the removal of TPHs by ryegrass. The removal rate of TPHs was significantly lower after the amendment of biochar. The results indicated that planting ryegrass is an effective remediation strategy, while the amendment of biochar may not be suitable for the phytoremediation of soil contaminated with petroleum hydrocarbons.
\end{abstract}

Keywords Petroleum hydrocarbons $\cdot$ Ryegrass $\cdot$ Biochar . Phytoremediation

Editorial Responsible: Hailong Wang

Yingying Wang

wangyy@nankai.edu.cn

1 Key Laboratory of Pollution Processes and Environmental Criteria (Ministry of Education), Tianjin Key Laboratory of Environmental Remediation and Pollution Control, College of Environmental Science and Engineering, Nankai University, Tianjin 300071, China

2 College of Life Sciences, Nankai University, Tianjin 300071, China

\section{Introduction}

The rapid development of the global economy has led to considerable environmental pollution by a wide range of persistent organic and inorganic pollutants (Gaskin and Bentham 2010; Zhang et al. 2010). Petroleum products are widely used in modern society and have become one of the most important environmental pollutants (Wang et al. 2010, 2012; Zhang et al. 2010). Petroleum is a mix of different compounds, consisting mainly of saturated hydrocarbons, aromatic hydrocarbons, resins, and asphaltenes (Liu et al. 2014). Petroleum is reported to cause environmental risks in the soil ecological system (Wang et al. 2012), such as inhibition of plant growth, damage to soil structure, destruction of groundwater quality, and so on (Cai et al. 2010). Moreover, the hazardous chemicals in petroleum also pose serious threats to human health (Anyika et al. 2015).

Considerable efforts have been made for the remediation of petroleum-contaminated sites. Phytoremediation is one of the most favorable remediation techniques since it is both costeffective and environmentally friendly (Gaskin et al. 2010; AlMansoory et al. 2015). Plants can have a number of effects, including degradation, transformation, assimilation, metabolism, and detoxification of hazardous pollutants from soils and aquatic and atmospheric sites (Cai et al. 2010). Several plant species, such as ryegrass, have been successfully applied to the phytoremediation of soil contaminated with organic and inorganic pollutants (Khan et al. 2013; Mimmo et al. 2015; Lu et al. 2015). The question of how to improve the efficiency and optimize the conditions of phytoremediation is one of the major concerns. It was reported that both the physicochemical properties and microbial activities of soil had a strong impact on the effectiveness of phytoremediation (Guo et al. 2014).

In recent years, the use of biochar as a soil amendment has been the subject of increasing attention (Tang et al. 2013). 
Biochar is formed by burning biomass under hypoxia and low temperature and is a low-density charred material (Bastos et al. 2014; Mukherjee et al. 2014; Tang et al. 2013). It was reported that biochar could change the soil physicochemical properties (Brennan et al. 2014). For example, it could increase the soil pH (Beesley and Marmiroli 2011; Mukherjee et al. 2014; Schmidt et al. 2014), strengthen the water retaining capacity of soil (Evangelou et al. 2014; Yao et al. 2012), raise the soil fertility (Mia et al. 2014; Steinbeiss et al. 2009), reduce the leaching of soluble macronutrients (Lucchini et al. 2014; Quilliam et al. 2013a), and heighten carbon sequestration (Bastos et al. 2014; Méndez et al. 2012). These lead to potentially beneficial effects on crop productivity, plant establishment, and growth; mitigating climate change by sequestrating $\mathrm{C}$ from atmosphere into soil; and improving moisture, nutrient retention, and microbial activity (Brennan et al. 2014). Meanwhile, biochar has also been used as a promising material in environmental remediation applications (Qin et al. 2013; Ahmad et al. 2014; GarciaDelgado et al. 2015). For instance, biochar has been applied as a novel carbonaceous material to adsorb metals in soil and water (Beesley et al. 2010; Ahmad et al. 2014). It was reported that biochar could reduce the toxicity and mobility of a lot of toxic metals (Gomez-Eyles et al. 2011; Oleszczuk et al. 2012). Due to its high surface area and microporosity, biochar has also been proven to be efficient in adsorbing organic contaminants in water (Lou et al. 2011; Ahmad et al. 2014). Compared to water remediation, relatively limited studies are available on the application of biochar in remediation of soil contaminated with organic pollutants (Ahmad et al. 2014). Most of the studies to date have focused on the use of biochar to bind or stimulate the microbial degradation of organic pollutants (Qin et al. 2013; Xin et al. 2014). For instance, biochar amendment was shown to promote the microbial degradation of petroleum-contaminated soil (Qin et al. 2013). However, little is currently known about the effects of biochar on the phytoremediation of petroleumcontaminated soil.

The aims of the current study were (1) to assess the potential of wheat straw-derived biochar amendments, ryegrass plant, and the combination of the two strategies on the removal of petroleum hydrocarbons and (2) to elucidate the effects of biochar on the phytoremediation of petroleumcontaminated soil by ryegrass and on the number of microorganisms in soil contaminated with petroleum hydrocarbons.

\section{Material and methods}

\section{Soil preparation}

Soil samples were taken from an un-contaminated farming area located in the Xiqing District of Tianjin, China. The soil was air-dried and passed through a 2-mm sieve to ensure the soil homogeneity. The crude oil was evenly sprayed in the soil, with a concentration of $10,000 \mathrm{mg} / \mathrm{kg}\left(1.0 \%, \mathrm{~W}_{\text {oil }} / \mathrm{W}_{\text {dry }}\right.$ soil). The soil was then blended and aired for 2 weeks before usage. The content of total petroleum hydrocarbons (TPHs) (day 0) was $7719 \pm 113 \mathrm{mg} / \mathrm{kg}$.

\section{Production and characterization of biochar}

The wheat straws were air-dried and milled or grounded to pass a 20 -mesh sieve. Biochar was produced at $450{ }^{\circ} \mathrm{C}$ under anaerobic conditions for $1 \mathrm{~h}$ using a slow pyrolysis process (Novak et al. 2009). Biochar was passed through a 100-mesh sieve before usage.

The pore structure of biochar was measured by nitrogen gas adsorption analysis at $77 \mathrm{~K}$ using ASAP 2020 Surface Area Analyzer (Brewer et al. 2009; Novak et al. 2009). Ash was measured at $600{ }^{\circ} \mathrm{C}$ for $6 \mathrm{~h}$. Biochar was dissolved in deionized water $(1 \% \mathrm{w} / \mathrm{v})$ and shaken for $24 \mathrm{~h}$ at $200 \mathrm{rpm}$ before the $\mathrm{pH}$ was measured (Novak et al. 2009). Contents of $\mathrm{C}, \mathrm{H}, \mathrm{N}$, and $\mathrm{S}$ elements were determined using the elemental analyzer (Euro, EA3000) (Brewer et al. 2009; Novak et al. 2009).

\section{Remediation treatments}

The ryegrass seeds were purchased from Suqian, Jiangsu, China. The pot culture experiments were carried out in the greenhouse. There were four treatments: control (designated as $\mathrm{C}$ treatment); amendment of biochar (1\%) only (designated as B treatment); planted ryegrass only (designated as P treatment); and planted ryegrass together with biochar amendment (1\%) (designated as PB treatment). Each treatment had three replicates. The ryegrass seeds were germinated for 1 week at $25{ }^{\circ} \mathrm{C}$ with $70 \%$ moisture content. Ten seedlings were then planted into the plastic pots $(\Phi 20 \mathrm{~cm} \times 20 \mathrm{~cm})$ containing $1500 \mathrm{~g}$ petroleum-contaminated soil. Fertilizer $(251.2 \mathrm{mg} /$ pot $\mathrm{N}, 157.0 \mathrm{mg} /$ pot $\mathrm{P}_{2} \mathrm{O}_{5}$, and $188.4 \mathrm{mg} /$ pot $\mathrm{K}_{2} \mathrm{O}$ ) was applied at the beginning of the experiment. The experiments were carried out in a greenhouse with natural sunlight and a light/dark cycle of approximately $16 / 8 \mathrm{~h}$ for 90 days. Samples were taken at day 0 and day 90 . The greenhouse temperature was kept at $18-25^{\circ} \mathrm{C}$, and soil moisture was maintained at $60 \%$ of the field water-holding capacity (WHC) by daily watering.

\section{Total petroleum hydrocarbon analysis}

The TPHs were determined as described before (Cai et al. 2010). A soil sample (100 g) was taken from each pot. Samples were air-dried at room temperature, passed through a 100 -mesh sieve, and stored at $4{ }^{\circ} \mathrm{C}$ for further analysis. Five grams of soil samples was dissolved in $20 \mathrm{ml}$ dichloromethane in a 40-ml glass centrifuge tube. The dichloromethane/soil 
suspension was agitated with a glass stirring rod for $1 \mathrm{~min}$ followed by extraction for $15 \mathrm{~min}$ using the ultrasonic method. During the extraction, the water bath was kept below $35^{\circ} \mathrm{C}$ by adding cold water. The suspension was then centrifuged for $10 \mathrm{~min}$ at $4000 \mathrm{rpm}$. The supernatant was then transferred into an Erlenmeyer flask, which was dried to a constant weight in an oven at $105^{\circ} \mathrm{C}$ in advance. The pellet was re-suspended in $20 \mathrm{ml}$ dichloromethane, and the above procedures were repeated three times. All the supernatants were combined and then completely evaporated at room temperature in a fume hood. The amount of the TPHs was calculated gravimetrically. The removal rate of TPHs was determined using the following equation:

Removal rate $(\%)=\frac{\mathrm{TPH}_{0}-\mathrm{TPH}_{90}}{\mathrm{TPH}_{0}} \times 100$

where $\mathrm{TPH}_{0}$ is the total petroleum hydrocarbons on day 0 and $\mathrm{TPH}_{90}$ is the total petroleum hydrocarbons after 90 days of incubation.

\section{Determination of alkanes and aromatic hydrocarbons}

The components of TPHs, including alkanes and aromatic hydrocarbons, were fractionated by silica gel and neutral alumina column chromatography followed by gravimetric analysis. A glass column $(\Phi 10 \mathrm{~mm} \times 300 \mathrm{~mm})$ was filled with $120 \mathrm{~mm}$ activated silica gel (pre-baked at $120{ }^{\circ} \mathrm{C}$ for $4 \mathrm{~h}$ ), $60 \mathrm{~mm}$ activated neutral alumina (pre-baked at $500{ }^{\circ} \mathrm{C}$ for $4 \mathrm{~h}$ ), and $10 \mathrm{~mm}$ anhydrous sodium sulfate (pre-baked at $500{ }^{\circ} \mathrm{C}$ for $4 \mathrm{~h}$ ). The TPHs were dissolved in a small amount of n-hexane and loaded onto the silica gel and neutral alumina column, which was pre-eluted with n-hexane. The saturated hydrocarbons were eluted with $20 \mathrm{ml} \mathrm{n}$-hexane, followed by a 70-ml n-hexane/dichloromethane (1:1) mixture to obtain the aromatic hydrocarbons. All elutes were completely evaporated at room temperature in a fume hood.

The n-alkanes and 16 priority polycyclic aromatic hydrocarbons (PAHs) dissolved in n-hexane were filtered through a $0.22-\mu \mathrm{m}$ nylon membrane filter and performed on a 7890 Agilent gas chromatograph coupled to a model 5975 mass selective detector (MSD; SIM mode). Hydrocarbon Window Defining Standard and PAH Solution Mix were purchased from AccuStandard, Inc. (New Haven, CT, USA). The nalkanes were separated with a He carrier gas $(1.5 \mathrm{ml} / \mathrm{min})$ on a $60-\mathrm{m}$ DB-5ms column, $0.250 \mathrm{~mm}$ internal diameter and $0.25 \mu \mathrm{m}$ film thickness. The following column oven program was used for n-alkane measurements: $40{ }^{\circ} \mathrm{C}$ for $2 \mathrm{~min}$, then ramped at $3{ }^{\circ} \mathrm{C} / \mathrm{min}$ to $300{ }^{\circ} \mathrm{C}$ for $55 \mathrm{~min}$. The PAHs were separated with a He carrier gas $(1.0 \mathrm{ml} / \mathrm{min})$ on a $30-\mathrm{m} \mathrm{HP}$ $5 \mathrm{~ms}$ column, $0.250 \mathrm{~mm}$ internal diameter and $0.25 \mu \mathrm{m}$ film thickness. The following column oven program was used for PAH measurements: $70^{\circ} \mathrm{C}$ for $1 \mathrm{~min}$, ramped at $10{ }^{\circ} \mathrm{C} / \mathrm{min}$ to
$260{ }^{\circ} \mathrm{C}$ for $4 \mathrm{~min}$, and then $5{ }^{\circ} \mathrm{C} / \mathrm{min}$ to $300{ }^{\circ} \mathrm{C}$ and held for $4 \mathrm{~min}$. An external standard method was used to calculate the amount of n-alkanes and PAHs.

\section{Ryegrass biomass and pigment analysis}

Ryegrass was harvested after the 90-day incubation. Plant samples were carefully grubbed from a pot with a handheld trowel and washed with tap water, followed by thorough rinsing with distilled water. Plants were air-dried at room temperature in the interior until the constant weight was reached. Shoot height, root length, and weight of plant were measured.

The fresh leaves were picked, cut up, and blended to measure the pigment content. Ten milliliters of extraction mixture (absolute ethyl alcohol/acetone/water 45:45:10) was added to the leaves and kept in the dark for a week at $4{ }^{\circ} \mathrm{C}$. Chlorophyll and carotenoid contents were measured spectrophotometrically at 663,645 , and $470 \mathrm{~nm}$ and calculated as previously reported (Arnon 1949).

\section{Flow cytometry analysis}

One gram of fresh soil samples was transferred into a 10-ml centrifuge tube followed by $5 \mathrm{ml}$ of sterile distilled water as solvent. The mixture was vortexed for $1 \mathrm{~min}$, followed by ultrasonication for $30 \mathrm{~s}$ (Ramsay 1984). The soil suspension was then centrifuged for $10 \mathrm{~min}$ at $3000 \mathrm{rpm}$. The supernatant was stained with $10 \mu \mathrm{l} / \mathrm{ml}^{-1}$ SYBR Green I $(100 \times$ in DMSO) for $15 \mathrm{~min}$ at room temperature in the dark. Sample was diluted with sterile distilled water prior to flow cytometry (FCM) analysis.

A Partec CyFlow Space flow cytometer (Partec GmbH, Münster, Germany) was used to measure the number of microbial cells. A blue solid-state laser at $50 \mathrm{~mW}$ in FCM emits at a fixed wavelength of $488 \mathrm{~nm}$. SYBR Green I was triggered on the green fluorescence at $520 \pm 20 \mathrm{~nm}$. Data were collected on two-parameter dot plots of green fluorescence as logarithmic signals. These measurements were made the specific instrumental gain settings-FL1 652, SSC 280, speed 3 (Ma et al. 2013). In order to calculate the moisture content, fresh soil was placed in an oven at $105^{\circ} \mathrm{C}$ for $24 \mathrm{~h}$, and the dry soil was weighed. The number of cells was adjusted to a dry soil weight basis.

\section{Statistical analysis}

Data and analysis of variance procedure (one-way ANOVA) for all treatments were conducted by the Microsoft Excel software and SPSS 18.0. The values were represented as mean \pm standard deviation (S.D.). The differences were analyzed at the 0.05 level. 


\section{Results}

\section{Characterization of biochar}

Detailed information regarding the characterization of biochar is shown in Table 1. Its specific surface area $\left(6.86 \mathrm{~m}^{2} / \mathrm{g}\right)$, micropore area $\left(0.17 \mathrm{~m}^{2} / \mathrm{g}\right)$, total pore volume $\left(22.29 \mathrm{~mm}^{3}\right.$ / $\mathrm{g})$, and micropore volume $\left(0.02 \mathrm{~mm}^{3} / \mathrm{g}\right)$ were very low compared with that of activated carbons (Brewer et al. 2009; Chen et al. 2014). Ash content and $\mathrm{pH}$ were $42.25 \%$ and 10.09 , respectively. Content of C element $(48.45 \%)$ was greater than that of $\mathrm{H}(1.78 \%), \mathrm{N}(1.47 \%)$, and $\mathrm{S}(0.78 \%)$ elements.

\section{The removal of TPHs}

The removal rate of TPHs using various treatments showed significant differences $(p<0.01)$ (Fig. 1). The removal of TPHs in soil contaminated with petroleum hydrocarbons was higher during the growth of ryegrass. The removal rate of TPHs in treatment P $(55.13 \%)$ was significantly higher $(p<0.01)$ than in the other treatments. After 90 days of incubation, the removal rate of TPHs under treatment $\mathrm{P}$ was 1.53 , 1.65 , and 1.60 times than that in treatments $\mathrm{C}, \mathrm{B}$, and $\mathrm{PB}$, respectively. However, the removal of TPHs in soil contaminated with petroleum hydrocarbons was restrained by the biochar. There were no significant differences among the treatments $\mathrm{B}, \mathrm{PB}$, and $\mathrm{C}(p>0.05)$. The removal rate in treatment $\mathrm{B}(33.45 \%)$ was slightly lower than that in treatment $\mathrm{C}$ $(36.08 \%)$ and treatment PB $(34.54 \%)$.

\section{Growth and pigment analysis of ryegrass}

Four parameters (e.g., shoot height, shoot dry weight, root length, and root fresh weight) were measured to assess the growth of ryegrass (Fig. 2). The amendment of biochar showed a negative effect on the growth of ryegrass (Fig. 2). There were significant differences between the shoot height, root length, and shoot dry weight of ryegrass in treatment PB

Table 1 Characterizatio$\mathrm{n}$ of biochar

\begin{tabular}{lr}
\hline Index & Value \\
\hline Specific surface area $\left(\mathrm{m}^{2} / \mathrm{g}\right)$ & 6.86 \\
Micropore area $\left(\mathrm{m}^{2} / \mathrm{g}\right)$ & 0.17 \\
Total pore volume $\left(\mathrm{mm}^{3} / \mathrm{g}\right)$ & 22.29 \\
Micropore volume $\left(\mathrm{mm}^{3} / \mathrm{g}\right)$ & 0.02 \\
Ash $(\mathrm{wt} \%)$ & 42.25 \\
$\mathrm{pH}$ & 10.09 \\
$\mathrm{C}(\mathrm{wt} \%)$ & 48.45 \\
$\mathrm{H}(\mathrm{wt} \%)$ & 1.78 \\
$\mathrm{~N}(\mathrm{wt} \%)$ & 1.47 \\
$\mathrm{~S}(\mathrm{wt} \%)$ & 0.78 \\
\hline
\end{tabular}

and those in treatment $\mathrm{P}(p<0.05)$. After 90 days, the shoot height, root length, and shoot dry weight in treatment $\mathrm{PB}$ were $17.38,16.74$, and $49.41 \%$ lower than those in treatment $\mathrm{P}$, respectively. In contrast, there was no significant difference in the root fresh weight of ryegrass between treatments PB and P.

Pigment content is one of the indicators of the cellular metabolic state. As shown in Fig. 3, all pigment parameters including chlorophyll, carotenoids, chlorophyll a/chlorophyll $\mathrm{b}$, and chlorophyll a/carotenoids showed no significant differences $(p>0.05)$ between treatments $\mathrm{P}$ and PB.

\section{Component changes in the process of phytoremediation}

The contents of petroleum hydrocarbon components decreased with time. The removal rate of total n-alkanes in treatment $\mathrm{P}(45.83 \%)$ was significantly higher $(p<0.01)$ than that in other treatments, and no significant differences were observed among the rest of the treatments (Fig. 1). For treatments $\mathrm{C}, \mathrm{B}$, and $\mathrm{PB}$, the removal rate was 5.57, 8.53, and $7.93 \%$ lower than that in treatment $\mathrm{P}$, respectively. Furthermore, there was a component change in n-alkane before and after incubation. The main n-alkane content after 90 days of incubation was $\mathrm{C}_{14}$ to $\mathrm{C}_{40}$. Moreover, the major removal of $n$-alkanes in treatment $P$ was $\mathrm{C}_{39}$ (Table 2).

The highest removal rate of total PAHs was also observed in treatment $\mathrm{P}(30.34 \%)$. There were no significant differences among the rest of the treatments. For treatments $\mathrm{C}, \mathrm{B}$, and $\mathrm{PB}$, the removal rate was $16.97,17.14$, and $16.04 \%$ lower than that in treatment $P$, respectively. The removal rate of total n-alkanes was greater than that of the total PAHs after a 90day incubation period (Fig. 1). Specifically, the total PAH content in all of the soils was 36-53 times lower than that of the total n-alkanes in each treatment, indicating that the removal of $n$-alkanes made a major contribution to the removal of TPHs. Furthermore, there was no clear component change in PAHs compared to n-alkanes. As shown in Fig. 4, four components (i.e., phenanthrene (PHE), pyrene (PYR), benz(a)anthracene (BaA), and chrysene (CHR)) accounted for $85.52-87.17 \%$ of the total PAHs in all treatments before and after incubation. The majority of the removal was also attributed to these four components (i.e., $34.58 \%$ for PHE, $16.93 \%$ for PYR, $34.78 \%$ for BaA, and $23.89 \%$ for CHR) in treatment $\mathrm{P}$.

The content of total n-alkanes and total PAHs in biochar was 47,100 and $3484 \mu \mathrm{g} / \mathrm{kg}$, accounting for 0.23 and $0.91 \%$ of those in the control at the start of the experiment, respectively. The main n-alkanes of biochar in soil/control soil were from $\mathrm{C}_{8}$ to $\mathrm{C}_{13}$, which accounted for $1.52-7.03 \%$. The main PAHs of biochar in soil/control soil were benzo(k)fluoranthene $(\mathrm{BkF})$, benzo(a)pyrene $(\mathrm{BaP})$, indeno(1,2,3-cd)pyrene (IcdP), and benzo(ghi)perylene (BghiP), which accounted for 37.69, 12.15, 9.31, and $4.82 \%$, respectively. 
Fig. 1 TPHs, n-alkanes, and PAH removal and microbial concentration in contaminated soil $\left(10 \mathrm{~g} \mathrm{~kg}^{-1}\right)$ under four different treatments after incubation for 90 days. Error bars represent the standard deviation from measurements in triplicate

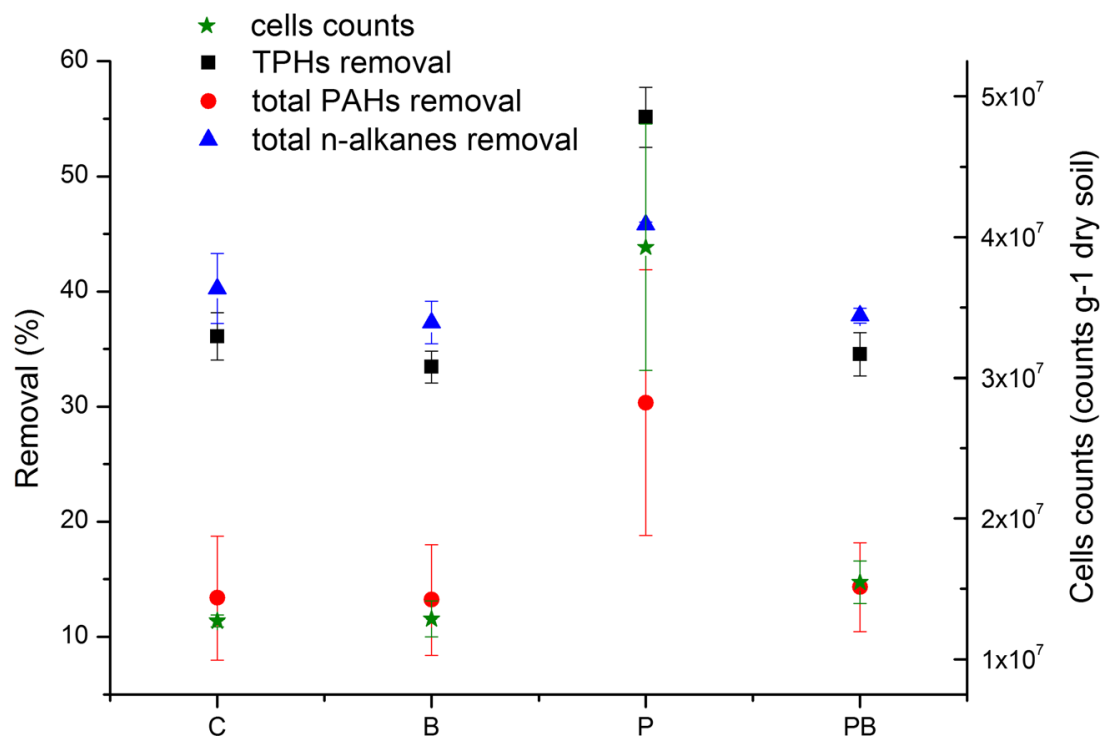

\section{Effects on total microbial count}

The concentration of microorganisms in soil contaminated with petroleum hydrocarbons was assessed and enumerated before and after remediation. A significant increase of microorganisms (from $2.91 \times 10^{6}$ to $1-4 \times 10^{7}$ cells/g dry soil) was observed in all treatments, suggesting growth of microorganisms on TPHs. In addition, significant differences $(p<0.01)$ in microbial biomass after incubation for 90 days were observed among the four treatments (Fig. 1). The number of microorganisms in treatment $\mathrm{P}\left(3.93 \times 10^{7}\right.$ cells/g dry soil $)$ was significantly higher $(p<0.01)$ than in the other three treatments. Specifically, the number of microorganisms in treatment $\mathrm{P}$ was $2.09,2.05$, and 1.54 times higher than that of treatments
$\mathrm{C}$, B, and $\mathrm{PB}$, respectively. The lowest microbial concentration was observed in treatment $\mathrm{C}\left(1.27 \times 10^{7}\right.$ cells/g dry soil $)$ where no amendment was added. Statistically, there were no significant differences $(p>0.05)$ among the microbial concentrations in treatments $\mathrm{C}, \mathrm{B}$, and $\mathrm{PB}$ after the 90-day incubation.

\section{Discussion}

The current study reports the efficiency of three petroleumcontaminated soil remediation strategies. The control treatment achieved $30 \%$ of TPH removal after 90 days of incubation, which is comparable to previous reports (Cai et al. 2010;
Fig. 2 Growth parameters of ryegrass, including shoot height, root length, shoot dry weight, and root dry weight, with (treatment PB) or without (treatment P) the amendment of biochar. Error bars represent the standard deviation
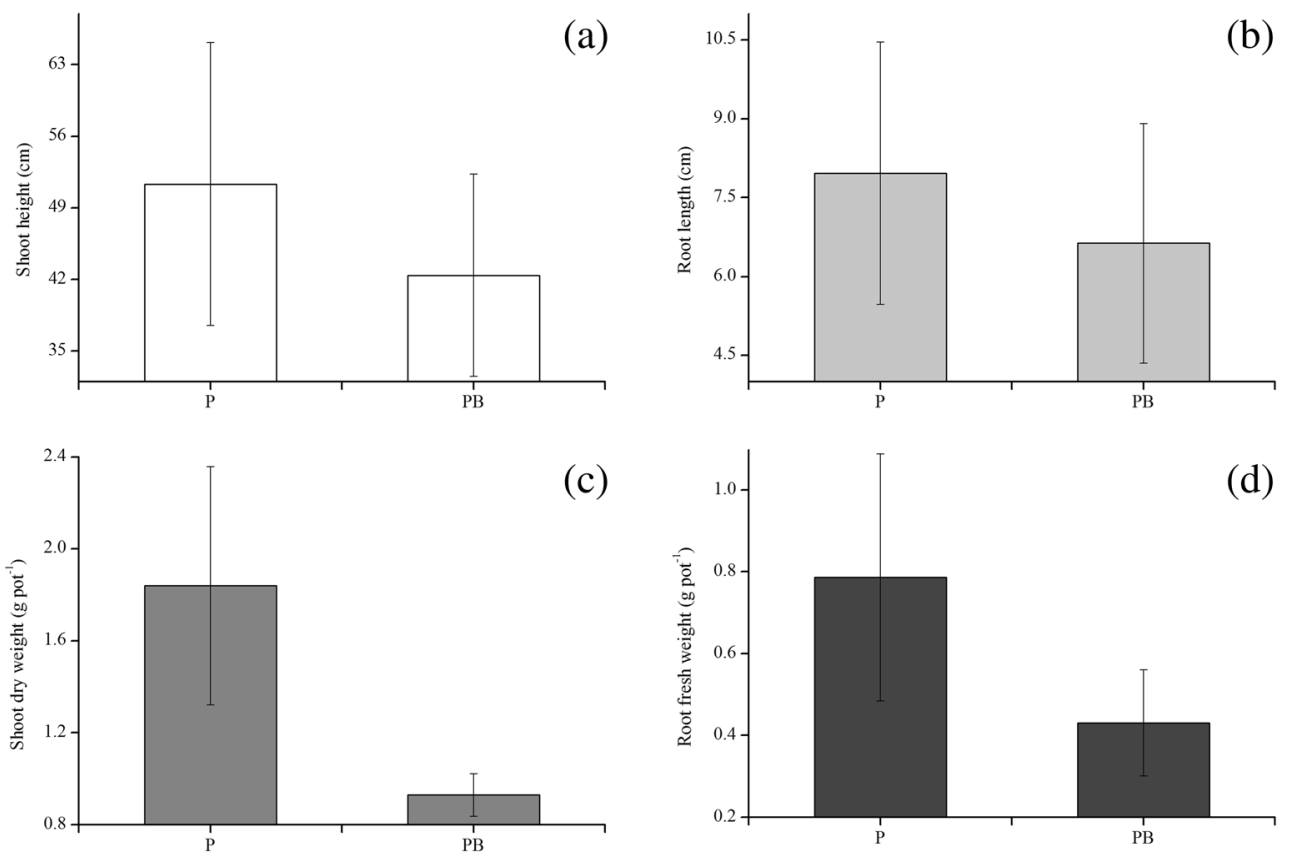

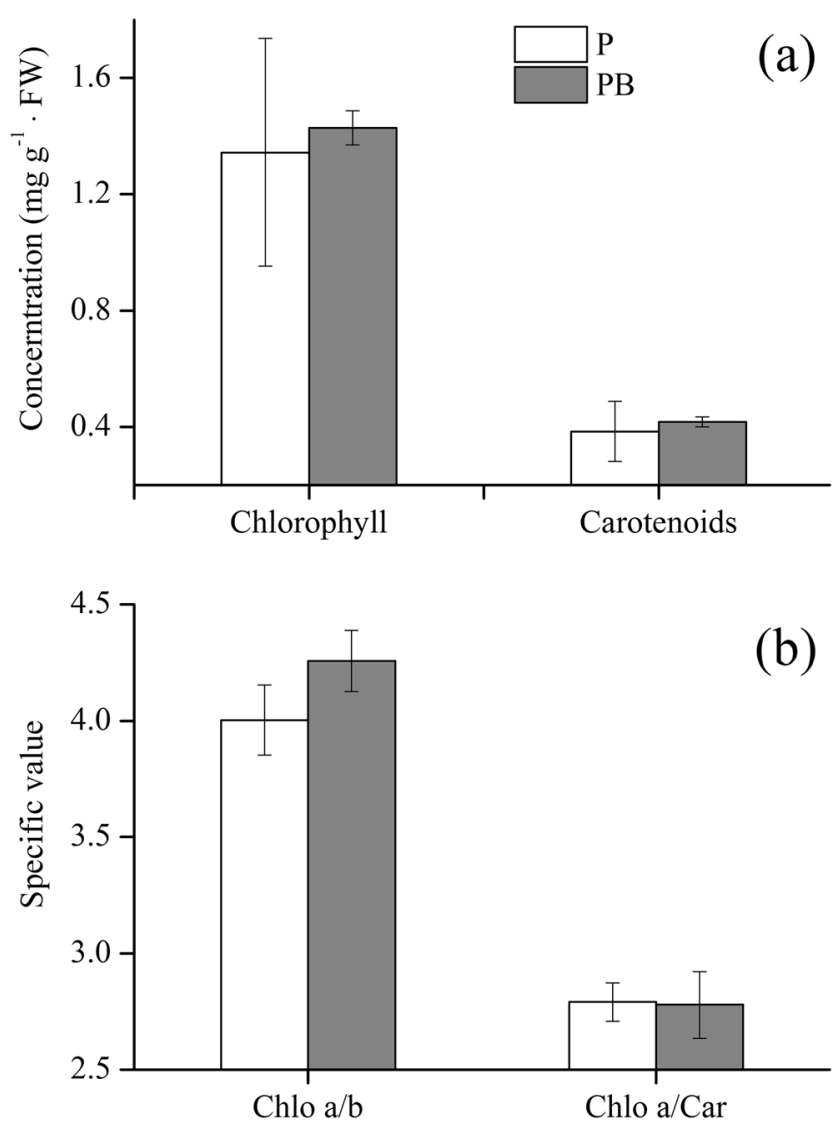

Fig. 3 Photosynthetic pigments including total chlorophyll, total carotenoids, chlorophyll a/b ratio, and chlorophyll a/carotenoid ratio of ryegrass with (treatment $\mathrm{PB}$ ) or without (treatment $\mathrm{P}$ ) the amendment of biochar. Error bars represent the standard deviation

Zhang et al. 2010). Fertilizer was applied at the beginning of the experiment, which could significantly enhance the microbial degradation of TPHs. It was reported that fertilizer application could promote the quantity of microorganism and bioremediation rates of environments polluted with petroleum hydrocarbons (Nikolopoulou et al. 2009; Mrozik et al. 2003). For example, it was observed that bacterial populations were stimulated by controlled release fertilizer application during phytoremediation of TPHs (Cartmill et al. 2014). In addition to microbial degradation, volatilization, eluviation, and photolysis were reported to play an important role in the removal of petroleum hydrocarbons (Zhang et al. 2010), which can also promote removal of TPHs in the control treatment.

The addition of biochar (treatment B) did not increase the effectiveness of TPH removal (Fig. 1), which is consistent with a previous study (Carcia-Delgado et al. 2015). Biochar contains many pores that may affect its function in the soil, e.g., smaller pores may influence molecule adsorption and transport, while larger pores are significant for water-holding capacity and aeration of soil. In essence, biochar contains a greater surface area because its pores have a far larger concentration than soil (Quilliam et al. 2013a). The porous physical properties of biochar provide an important habitat niche for microorganisms, which may be the most common explanation for why biochar can increase the abundance and activity of soil microorganisms (Pietikäinen et al. 2000). However, its contribution is small (Quilliam et al. 2013a). Studies have shown that biochar barely affects the composition of the soil microbial community (Steinbeiss et al. 2009). Our study has shown that after burial in the soil for 3 months, despite the significant reduction in the number of microorganisms compared to the plant treatment, biochar had no significant impact on other treatments. This was less likely to be due to surface area and pore volume in our study. Biochar could also affect soil properties, e.g., significantly increased soil $\mathrm{pH}$ and soil $\mathrm{C}$, increased sub-nanopore surface area, reduced soil bulk density, and so on (Mukherjee et al. 2014). However, relative to the soil, the contribution of biochar is very low in the total soil pore space and the total soil surface area. Furthermore, a large proportion of the biochar pores were less than $1 \mu \mathrm{m}$ in diameter, which is effectively uninhabitable for most microbes. Biochar has a lower available $\mathrm{C}$ status and differs in the structure of the microbial community relative to the surrounding soil. At least in the short term, biochar cannot provide a meaningful habitat for microbes (Quilliam et al. 2013a). One reason may be that biochar often introduces high concentrations of mineral salts and PAHs, which can have a negative impact on the microbial colony (Boonchan et al. 2000).

The results obtained in this study offer clear evidence that phytoremediation with ryegrass was more efficient in the removal of TPHs than the other treatments used (Fig. 1). It was reported that ryegrass could be applied to the phytoremediation of hydrocarbon-polluted soil (Arslan et al. 2014) and herbicide-contaminated solutions (Mimmo et al. 2015). The fact that majority of the removal of n-alkanes happened to $\mathrm{C}_{39}$ (Table 2) indicates that ryegrass has the potential to be applied in the phytoremediation of long-chain alkanes. Furthermore, four major components of PAHs accounted for about $80 \%$ of the total removal of PAHs. The results are consistent with previous report where PHE, PYR, and CHR contributed to $75 \%$ of the PAH removal (Wang et al. 2012).

Plants have been shown to play an important role in the process of remediation (Liu et al. 2014; Rodríguez-Vila et al. 2014). Plants may add an increased number of microorganisms, improve soil physicochemical properties, and increase the humification and adsorption of pollutants in the rhizosphere to cause the removal of petroleum hydrocarbons (Al-Mansoory et al. 2015). In the current study, the ryegrass showed a promoting effect on the removal of petroleum hydrocarbons in soil. This may be due to the joint actions of plants and microorganisms (Khan et al. 2013; Zhang et al. 2010). The microbial number also reached the highest in treatment $P$ (Fig. 1). It was reported that plants and their associated bacteria interact with each other during phytoremediation (Khan et al. 2013). Plant growth can provide nutrition and promote growth of rhizosphere 
Table 2 Concentration of various components of $n$-alkanes $(\mu \mathrm{g} / \mathrm{kg} \cdot \mathrm{dry}$ soil) before incubation (day 0 ) and after 90 days of incubation in different treatments $(\mathrm{C}, \mathrm{P}, \mathrm{B}, \mathrm{PB})$

\begin{tabular}{|c|c|c|c|c|c|}
\hline n-Alkanes & $\begin{array}{l}\text { Day } 0 \\
(\mu \mathrm{g} / \mathrm{kg} \text { dry soil) }\end{array}$ & $\begin{array}{l}\mathrm{C}(\mu \mathrm{g} / \mathrm{kg} \\
\text { dry soil })\end{array}$ & $\begin{array}{l}\mathrm{P}(\mu \mathrm{g} / \mathrm{kg} \\
\text { dry soil) }\end{array}$ & $\begin{array}{l}\text { B }(\mu \mathrm{g} / \mathrm{kg} \\
\text { dry soil) }\end{array}$ & $\begin{array}{l}\mathrm{PB}(\mu \mathrm{g} / \mathrm{kg} \\
\text { dry soil) }\end{array}$ \\
\hline $\mathrm{C} 8$ & $25 \pm 3$ & $54 \pm 8$ & $43 \pm 1$ & $53 \pm 1$ & $56 \pm 4$ \\
\hline C9 & $17 \pm 3$ & $16 \pm 5$ & $11 \pm 2$ & $13 \pm 0$ & $16 \pm 3$ \\
\hline $\mathrm{C} 10$ & $4 \pm 1$ & $6 \pm 0$ & $6 \pm 0$ & $7 \pm 0$ & $7 \pm 0$ \\
\hline $\mathrm{C} 11$ & $14 \pm 3$ & $26 \pm 1$ & $31 \pm 14$ & $27 \pm 2$ & $26 \pm 1$ \\
\hline $\mathrm{C} 12$ & $14 \pm 4$ & $19 \pm 1$ & $17 \pm 2$ & $18 \pm 2$ & $17 \pm 1$ \\
\hline $\mathrm{C} 13$ & $39 \pm 17$ & $27 \pm 5$ & $23 \pm 3$ & $32 \pm 5$ & $23 \pm 0$ \\
\hline $\mathrm{C} 14$ & $309 \pm 107$ & $145 \pm 61$ & $153 \pm 99$ & $301 \pm 205$ & $133 \pm 76$ \\
\hline $\mathrm{C} 15$ & $787 \pm 172$ & $312 \pm 148$ & $300 \pm 111$ & $428 \pm 225$ & $313 \pm 125$ \\
\hline $\mathrm{C} 16$ & $1923 \pm 347$ & $1140 \pm 326$ & $1095 \pm 229$ & $1370 \pm 498$ & $1272 \pm 293$ \\
\hline $\mathrm{C} 17$ & $2881 \pm 355$ & $1725 \pm 390$ & $1581 \pm 228$ & $1810 \pm 459$ & $1889 \pm 148$ \\
\hline $\mathrm{C} 18$ & $3121 \pm 352$ & $2478 \pm 293$ & $2172 \pm 205$ & $2505 \pm 225$ & $2618 \pm 155$ \\
\hline C19 & $3613 \pm 340$ & $2836 \pm 258$ & $2515 \pm 114$ & $2833 \pm 192$ & $2924 \pm 107$ \\
\hline $\mathrm{C} 20$ & $5749 \pm 598$ & $4711 \pm 183$ & $4242 \pm 88$ & $4774 \pm 38$ & $4914 \pm 122$ \\
\hline $\mathrm{C} 21$ & $6752 \pm 648$ & $5658 \pm 68$ & $5068 \pm 43$ & $5671 \pm 17$ & $5842 \pm 123$ \\
\hline $\mathrm{C} 22$ & $7662 \pm 746$ & $6655 \pm 209$ & $6029 \pm 36$ & $6687 \pm 101$ & $6922 \pm 235$ \\
\hline $\mathrm{C} 23$ & $8885 \pm 818$ & $7781 \pm 207$ & $7157 \pm 66$ & $7744 \pm 89$ & $8086 \pm 164$ \\
\hline $\mathrm{C} 24$ & $9661 \pm 994$ & $8380 \pm 272$ & $7714 \pm 105$ & $8204 \pm 94$ & $8642 \pm 155$ \\
\hline $\mathrm{C} 25$ & $11,058 \pm 1315$ & $9251 \pm 300$ & $8591 \pm 130$ & $8991 \pm 192$ & $9448 \pm 77$ \\
\hline $\mathrm{C} 26$ & $11,866 \pm 1192$ & $9353 \pm 309$ & $9198 \pm 86$ & $9068 \pm 179$ & $9672 \pm 311$ \\
\hline $\mathrm{C} 27$ & $10,598 \pm 1166$ & $7731 \pm 310$ & $7256 \pm 69$ & $7529 \pm 177$ & $7835 \pm 51$ \\
\hline $\mathrm{C} 28$ & $9092 \pm 1119$ & $6073 \pm 257$ & $5715 \pm 83$ & $5819 \pm 82$ & $6138 \pm 22$ \\
\hline $\mathrm{C} 29$ & $9436 \pm 1412$ & $5853 \pm 283$ & $5534 \pm 103$ & $5719 \pm 180$ & $5914 \pm 37$ \\
\hline $\mathrm{C} 30$ & $10,906 \pm 1855$ & $6237 \pm 393$ & $5975 \pm 390$ & $6269 \pm 586$ & $6754 \pm 16$ \\
\hline C31 & $11,111 \pm 1473$ & $5892 \pm 220$ & $5620 \pm 194$ & $5890 \pm 184$ & $5985 \pm 48$ \\
\hline $\mathrm{C} 32$ & $8257 \pm 1319$ & $3802 \pm 296$ & $3737 \pm 131$ & $4065 \pm 222$ & $3992 \pm 27$ \\
\hline $\mathrm{C} 33$ & $8879 \pm 1530$ & $3809 \pm 241$ & $3634 \pm 125$ & $3996 \pm 138$ & $4007 \pm 117$ \\
\hline $\mathrm{C} 34$ & $7995 \pm 1573$ & $3015 \pm 203$ & $2795 \pm 154$ & $3287 \pm 123$ & $3236 \pm 74$ \\
\hline $\mathrm{C} 35$ & $8132 \pm 1489$ & $3072 \pm 249$ & $2868 \pm 136$ & $3380 \pm 135$ & $3237 \pm 22$ \\
\hline $\mathrm{C} 36$ & $7246 \pm 1430$ & $2144 \pm 187$ & $1940 \pm 133$ & $2486 \pm 119$ & $2320 \pm 69$ \\
\hline $\mathrm{C} 37$ & $12,453 \pm 2504$ & $3662 \pm 375$ & $3227 \pm 183$ & $4305 \pm 204$ & $3997 \pm 149$ \\
\hline $\mathrm{C} 38$ & $7916 \pm 1194$ & $2399 \pm 248$ & $2097 \pm 94$ & $2770 \pm 165$ & $2552 \pm 113$ \\
\hline C39 & $8537 \pm 1280$ & $2378 \pm 163$ & $2098 \pm 66$ & $2609 \pm 124$ & $2008 \pm 790$ \\
\hline $\mathrm{C} 40$ & $10,154 \pm 568$ & $5893 \pm 1093$ & $2667 \pm 971$ & $10,241 \pm 454$ & $6867 \pm 517$ \\
\hline Sum & $205,100 \pm 27,927$ & $122,533 \pm 6233$ & $111,109 \pm 463$ & $128,901 \pm 3785$ & $127,662 \pm 1339$ \\
\hline
\end{tabular}

microorganisms. In return, microorganisms can increase the plant nutrient supply, and adding plant resistance to poisons or reducing poisonous bioavailability in the rhizosphere may help plant growth. For example, some plant-associated bacteria can produce biosurfactants that can enhance the bioavailability of hydrocarbons and may be useful for phytoremediation applications (Pacwa-Płociniczak et al. 2011). These microorganisms can secrete plant hormones and promote the absorption of nutrients in the soil, which not only directly stimulates plant growth but also improves the adaptation of plants to drought, salinity, and toxicity of metals and organic pollutants (Das and Tiwary 2014). Taken together, the synergistic effects between plants and their associated microorganisms is a feasible "clean up" technology in the removal of hydrocarbon pollutants for the remediation of contaminated soils (Gaskin and Bentham 2010).

The results presented here showed that the amendment of biochar played a negative role in the phytoremediation of petroleum-contaminated soil (Fig. 1) as well as the growth of ryegrass (Figs. 2 and 3). It is known that biochar contains petroleum hydrocarbons which may have toxicity to plants and microorganisms (Oleszczuk et al. 2013; Quilliam et al. 2013b). During a slow and long pyrolysis, PAHs are more easily lost to the atmosphere, whereas they are more readily concentrated in the biochar surface during a fast pyrolysis (Hale et al. 2012). However, compared to petroleum 

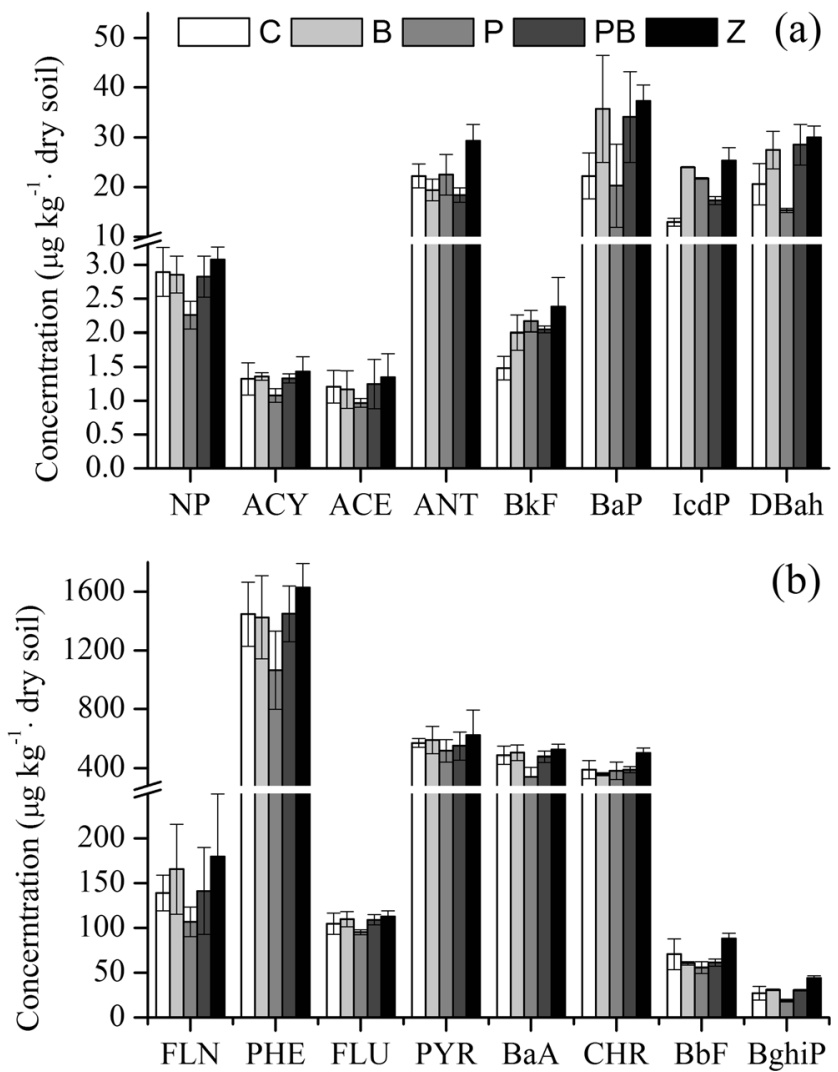

Fig. 4 Components of PAHs at day 0 (labeled as $Z$ ) and after 90 days of incubation in four different treatments (i.e., C, B, P, PB). NP: naphthalene; $A C Y$ acenaphthylene; $A C E$ acenaphthylene; $F L N$ fluorene; $P H E$ phenanthrene; $A N T$ anthracene; FLU fluoranthene; $P Y R$ pyrene; $B a A$ benzo(a)anthracene; $C H R$ chrysene; $B b F$ benzo(b)fluoranthene; $B k F$ benzo(k)fluoranthene; $B a P$ benzo(a)pyrene; $I c d P$ indeno(1,2,3cd)pyrene; DBah dibenzo(a,h)anthracene; BghiP benzo(ghi)perylene. Error bars represent the standard deviation from triplicate measurements

hydrocarbons applied to the soil in the current study, the alkanes $(47 \mathrm{mg} / \mathrm{kg})$ and PAHs $(3.5 \mathrm{mg} / \mathrm{kg})$ contained in the biochar can be neglected. It is therefore possible that other properties of the biochar affected the removal of petroleum hydrocarbons. Biochar in the soil can strongly adsorb soil nutrients and organic matter, which can jam the pores and reduce the available pore volume and surface area of biochar (Joseph et al. 2010). In addition, biochar may reduce soil nutrient leaching (e.g., nitrate, ammonium, phosphate, and microelement) (Beesley and Marmiroli 2011; Gomez-Eyles et al. 2011; Guo et al. 2014; Ippolito et al. 2012; Schmidt et al. 2014; Yao et al. 2012) and can impact $C$ and nutrient bioavailability in the charosphere (Quilliam et al. 2013a), which limits the use of nutrients in plants and microorganisms.

It was reported that biochar did not have a significantly positive effect on plant yield (Evangelou et al. 2014; Lucchini et al. 2014; Mia et al. 2014; Schmidt et al. 2014). Biochar can increase the sorption of organic pollutants (Chen and Yuan 2011; Ippolito et al. 2012; Oleszczuk et al. 2012; Quilliam et al. 2013b; Tang et al. 2013). In particular, PAHs adsorbed by biochar per unit mass can be 10-1000 times more than other types of organic $\mathrm{C}$ in soils (Accardi-Dey and Gschwend 2003; Rhodes et al. 2010). A large number of studies have shown that biochar can also reduce bioavailability of organic pollutants (Ippolito et al. 2012; Quilliam et al. 2013b) through adsorbing nutrients (Joseph et al. 2010) and producing toxicity to microorganisms (Oleszczuk et al. 2013; Quilliam et al. 2013b). In general, biochar may make the soil a nutrient poor and potentially toxic environment for plants and microorganisms to colonize.

\section{Conclusions}

This work demonstrated that bioremediation strategies for petroleum-contaminated soil $(1 \%)$ with phytoremediation using ryegrass were more efficient than non-amended soil or biochar application. The phytoremediation with ryegrass achieved effective removal of petroleum hydrocarbons (55.13\% for TPHs, $30.34 \%$ for PAHs, and $45.83 \%$ for $\mathrm{n}$ alkanes) over a 90-day incubation period. It was clearly shown that ryegrass could promote the growth of microorganisms in the contaminated soils with $10,000 \mathrm{mg} / \mathrm{kg}$ of TPHs. Although the amendment of biochar did not cause significant negative influences on soil microflora, it suppressed the growth and development of ryegrass. In general, ryegrass can effectively promote the removal of TPHs for petroleum-contaminated soil, and the removal efficiency was restrained under the effects of biochar. Our results suggest that the amendment of biochar is not suitable for phytoremediation of petroleumcontaminated soil.

Acknowledgments This work was supported by the National Key Basic Research Program of China [2015CB459000], the Innovation Research Team Program, Ministry of Education China [IRT 13024], and the National Science Foundation of China [31270545]. The authors would like to thank Prof. Qixing Zhou for providing the greenhouse.

Open Access This article is distributed under the terms of the Creative Commons Attribution 4.0 International License (http:// creativecommons.org/licenses/by/4.0/), which permits unrestricted use, distribution, and reproduction in any medium, provided you give appropriate credit to the original author(s) and the source, provide a link to the Creative Commons license, and indicate if changes were made.

\section{References}

Accardi-Dey AM, Gschwend PM (2003) Reinterpreting literature sorption data considering both absorption into organic carbon and adsorption onto black carbon. Environ Sci Technol 37(1):99-106

Ahmad M, Rajapaksha AU, Lim JE, Zhang M, Bolan N, Mohan D, Vithanage M, Lee SS, Ok YS (2014) Biochar as a sorbent for contaminant management in soil and water: A review. Chemosphere 99: $19-33$ 
Al-Mansoory AF, Idris M, Abdullah SRS, Anuar N (2015) Phytoremediation of contaminated soils containing gasoline using Ludwigia octovalvis (Jacq.) in greenhouse pots. Environ Sci Pollut Res:1-11

Anyika C, Majid ZA, Ibrahim Z, Zakaria MP, Yahya A (2015) The impact of biochars on sorption and biodegradation of polycyclic aromatic hydrocarbons in soils - a review. Environ Sci Pollut Res 22(5): 3314-3341

Arnon I (1949) Copper enzymes in isolated chloroplasts: polyphenoloxidase in Beta vulgaris. Plant Physiol 24:1-15

Arslan M, Afzal M, Amin I, Iqbal S, Khan QM (2014) Nutrients can enhance the abundance and expression of alkane hydroxylase CYP153 Gene in the rhizosphere of ryegrass planted in hydrocarbon-polluted soil. PLoS ONE 9(10): e111208

Bastos AC, Prodana M, Abrantes N, Keizer JJ, Soares AMVM, Loureiro S (2014) Potential risk of biochar-amended soil to aquatic systems: an evaluation based on aquatic bioassays. Ecotoxicology 23(9): 1784-1793

Beesley L, Marmiroli M (2011) The immobilisation and retention of soluble arsenic, cadmium and zinc by biochar. Environ Pollut 159(2):474-480

Beesley L, Moreno-Jiménez E, Gomez-Eyles JL (2010) Effects of biochar and greenwaste compost amendments on mobility, bioavailability and toxicity of inorganic and organic contaminants in a multi-element polluted soil. Environ Pollut 158(6):2282-2287

Boonchan S, Britz ML, Stanley G (2000) Degradation and mineralization of high-molecular-weight polycyclic aromatic hydrocarbons by defined fungal-bacterial cocultures. Appl Environ Microbiol 66(3): 1007-1019

Brennan A, Jiménez EM, Alburquerque JA, Knapp CW, Switzer C (2014) Effects of biochar and activated carbon amendment on maize growth and the uptake and measured availability of polycyclic aromatic hydrocarbons (PAHs) and potentially toxic elements (PTEs). Environ Pollut 193:79-87

Brewer CE, Schmidt-Rohr K, Satrio JA, Brown RC (2009) Characterization of biochar from fast pyrolysis and gasification systems. Environ Prog Sustain Energy 28(3):386-396

Cai Z, Zhou Q, Peng S, Li K (2010) Promoted biodegradation and microbiological effects of petroleum hydrocarbons by Impatiens balsamina L. with strong endurance. J Hazard Mater 183(1):731737

Cartmill AD, Cartmill DL, Alarcón A (2014) Controlled release fertilizer increased phytoremediation of petroleum contaminated sandy soil. Int J Phytoremediation 16(3):285-301

Chen B, Yuan M (2011) Enhanced sorption of polycyclic aromatic hydrocarbons by soil amended with biochar. J Soils Sediments 11(1): $62-71$

Chen Z, Li K, Pu L (2014) The performance of phosphorus (P)-doped activated carbon as a catalyst in air-cathode microbial fuel cells. Bioresour Technol 170:379-384

Das R, Tiwary BN (2014) Production of indole acetic acid by a novel bacterial strain of Planomicrobium chinense isolated from diesel oil contaminated site and its impact on the growth of Vigna radiate. Eur J Soil Biol 62:92-100

Evangelou MWH, Brem A, Ugolini F, Abiven S, Schulin R (2014) Soil application of biochar produced from biomass grown on trace element contaminated land. J Environ Manag 146:100-106

Garcia-Delgado C, Alfaro-Barta I, Eymar E (2015) Combination of biochar amendment and mycoremediation for polycyclic aromatic hydrocarbons immobilization and biodegradation in creosotecontaminated soil. J Hazard Mater 285:259-266

Gaskin SE, Bentham RH (2010) Rhizoremediation of hydrocarbon contaminated soil using Australian native grasses. Sci Total Environ 408(17):3683-3688

Gomez-Eyles JL, Sizmur T, Collins CD, Hodson ME (2011) Effects of biochar and the earthworm Eisenia fetida on the bioavailability of polycyclic aromatic hydrocarbons and potentially toxic elements. Environ Pollut 159(2):616-622

Guo Y, Tang H, Li G, Xie D (2014) Effects of cow dung biochar amendment on adsorption and leaching of nutrient from an acid yellow soil irrigated with biogas slurry. Water Air Soil Pollut 225(1):1-13

Hale SE, Lehmann J, Rutherford D, Zimmerman AR, Bachmann RT, Shitumbanuma V, Cornelissen G (2012) Quantifying the total and bioavailable polycyclic aromatic hydrocarbons and dioxins in biochars. Environ Sci Technol 46(5):2830-2838

Ippolito JA, Laird DA, Busscher WJ (2012) Environmental benefits of biochar. J Environ Qual 41(4):967-972

Joseph SD, Camps-Arbestain M, Lin Y, Munroe P, Chia CH, Hook J, Lehmann J (2010) An investigation into the reactions of biochar in soil. Soil Res 48(7):501-515

Khan S, Afzal M, Iqbal S, Khan QM (2013) Plant-bacteria partnerships for the remediation of hydrocarbon contaminated soils. Chemosphere 90:1317-1332

Liu H, Yao J, Yuan Z, Shang Y, Chen H, Wang F, Choi MM (2014) Isolation and characterization of crude-oil-degrading bacteria from oil-water mixture in Dagang oilfield, China. Int Biodeterior Biodegrad 87:52-59

Lou L, Wu B, Wang L, Luo L, Xu X, Hou J, Xun B, Hu B, Chen Y (2011) Sorption and ecotoxicity of pentachlorophenol polluted sediment amended with rice-straw derived biochar. Bioresour Technol 102(5):4036-4041

Lu H, Li Z, Fu S, Mendez A, Gasco G, Paz-Ferreiro J (2015) Combining phytoextraction and biochar addition improves soil biochemical properties in a soil contaminated with Cd. Chemosphere 119:209 216

Lucchini P, Quilliam RS, DeLuca TH, Vamerali T, Jones DL (2014) Increased bioavailability of metals in two contrasting agricultural soils treated with waste wood-derived biochar and ash. Environ Sci Pollut Res 21(5):3230-3240

Ma L, Mao G, Liu J, Yu H, Gao G, Wang Y (2013) Rapid quantification of bacteria and viruses in influent, settled water, activated sludge and effluent from a wastewater treatment plant using flow cytometry. Water Sci Technol 68(8):1763-1769

Méndez A, Gómez A, Paz-Ferreiro J, Gascó G (2012) Effects of sewage sludge biochar on plant metal availability after application to a Mediterranean soil. Chemosphere 89(11):1354-1359

Mia S, van Groenigen JW, Van de Voorde TFJ, Oram NJ, Bezemer TM, Mommer L, Jeffery S (2014) Biochar application rate affects biological nitrogen fixation in red clover conditional on potassium availability. Agric Ecosyst Environ 191:83-91

Mimmo T, Bartucca ML, Buono DD, Cesco S (2015) Italian ryegrass for the phytoremediation of solutions polluted with terbuthylazine. Chemosphere 119:31-36

Mrozik A, Piotrowska-Seget Z, Labuzek S (2003) Bacterial degradation and bioremediation of polycyclic aromatic hydrocarbons. Pol J Environ Stud 12(1):15-25

Mukherjee A, Lal R, Zimmerman AR (2014) Effects of biochar and other amendments on the physical properties and greenhouse gas emissions of an artificially degraded soil. Sci Total Environ 487:26-36

Nikolopoulou M, Kalogerakis N (2009) Biostimulation strategies for fresh and chronically polluted marine environments with petroleum hydrocarbons. J Chem Technol Biotechnol 84(6): 802-807

Novak JM, Lima I, Xing B, Gaskin JW, Steiner C, Das KC, Schomberg H (2009) Characterization of designer biochar produced at different temperatures and their effects on a loamy sand. Annal Environ Sci 3:195-206

Oleszczuk P, Hale SE, Lehmann J, Cornelissen G (2012) Activated carbon and biochar amendments decrease pore-water concentrations of polycyclic aromatic hydrocarbons (PAHs) in sewage sludge. Bioresour Technol 111:84-91 
Oleszczuk P, Jośko I, Kuśmierz M (2013) Biochar properties regarding to contaminants content and ecotoxicological assessment. J Hazard Mater 260:375-382

Pacwa-Płociniczak M, Płaza GA, Piotrowska-Seget Z, Cameotra SS (2011) Environmental applications of biosurfactants: recent advances. Int J Mol Sci 12(1):633-654

Pietikäinen J, Kiikkilä O, Fritze H (2000) Charcoal as a habitat for microbes and its effect on the microbial community of the underlying humus. Oikos 89(2):231-242

Qin G, Gong D, Fan MY (2013) Bioremediation of petroleumcontaminated soil by biostimulation amended with biochar. Int Biodeterior Biodegrad 85:150-155

Quilliam RS, Rangecroft S, Emmett BA, Deluca TH, Jones DL (2013a) Is biochar a source or sink for polycyclic aromatic hydrocarbon (PAH) compounds in agricultural soils? GCB Bioenergy 5(2):96-103

Quilliam RS, Glanville HC, Wade SC, Jones DL (2013b) Life in the 'charosphere' - does biochar in agricultural soil provide a significant habitat for microorganisms? Soil Biol Biochem 65:287-293

Ramsay AJ (1984) Extraction of bacteria from soil: efficiency of shaking or ultrasonication as indicated by direct counts and autoradiography. Soil Biol Biochem 16(5):475-481

Rhodes AH, McAllister LE, Chen R, Semple KT (2010) Impact of activated charcoal on the mineralisation of ${ }^{14} \mathrm{C}$-phenanthrene in soils. Chemosphere 79(4):463-469

Rodríguez-Vila A, Covelo EF, Forjan R, Asensio V (2014) Phytoremediation a copper mine soil with Brassica juncea L., compost and biochar. Environ Sci Pollut Res 21:11293-11304
Schmidt HP, Kammann C, Niggli C, Evangelou MW, Mackie KA, Abiven S (2014) Biochar and biochar-compost as soil amendments to a vineyard soil: influences on plant growth, nutrient uptake, plant health and grape quality. Agric Ecosyst Environ 191:117-123

Steinbeiss S, Gleixner G, Antonietti M (2009) Effect of biochar amendment on soil carbon balance and soil microbial activity. Soil Biol Biochem 41(6):1301-1310

Tang J, Zhu W, Kookana R, Katayama A (2013) Characteristics of biochar and its application in remediation of contaminated soil. J Biosci Bioeng 116(6):653-659

Wang X, Cai Z, Zhou Q, Zhang Z, Chen C (2012) Bioelectrochemical stimulation of petroleum hydrocarbon degradation in saline soil using U-tube microbial fuel cells. Biotechnol Bioeng 109(2):426433

Wang X, Feng J, Zhao J (2010) Effects of crude oil residuals on soil chemical properties in oil sites, Momoge Wetland, China. Environ Monit Assess 161(1-4):271-280

Xin J, Liu X, Liu W, Zheng XL (2014) Effects of biochar-BDE-47 interactions on BDE-47 bioaccessibility and biodegradation by Pseudomonas putida TZ-1. Ecotox Environ Safe 106:27-32

Yao Y, Gao B, Zhang M, Inyang M, Zimmerman AR (2012) Effect of biochar amendment on sorption and leaching of nitrate, ammonium, and phosphate in a sandy soil. Chemosphere 89(11):1467-1471

Zhang Z, Zhou Q, Peng S, Cai Z (2010) Remediation of petroleum contaminated soils by joint action of Pharbitis nil L. and its microbial community. Sci Total Environ 408(22):5600-5605 